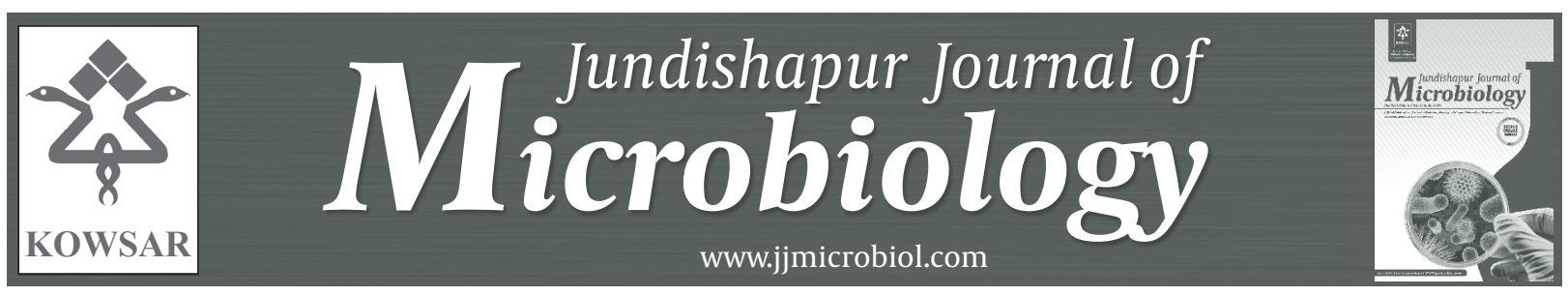

\title{
Using Rice Flour for Purification of Maltose Binding Fusion Proteins Ex- pressed in Escherichia coli
}

\author{
Azadeh Neissi ${ }^{1}$, Masoudreza Seyfi Abad Shapouri ${ }^{1,}{ }^{*}$, Masoud Ghorbanpoor Najafabadi ${ }^{1}$, \\ Amin Jaydary ${ }^{2}$ \\ ${ }^{1}$ Department of Pathobiology, School of Veterinary Medicine, Shahid Chamran University, Ahvaz, IR Iran \\ 2 Department of Pathobiology, School of Veterinary Medicine, University of Lorestan, Khorram Abad, IR Iran \\ ${ }^{*}$ Corresponding author Masoudreza Seyfi Abad Shapouri, School of Veterinary Medicine, Shahid Chamran University, Ahvaz, IR Iran. Tel: +989161133247, Fax: \\ +98-6113360807, E-mail: masoudrs@yahoo.com.
}

\section{A B S T R A C T}

Background: One disadvantage of expressing heterologous proteins in Escherichia coli is that the proteins are frequently expressed as insoluble inclusion bodies. To avoid this problem, heterologous proteins are typically expressed as a fusion protein. Maltose binding protein (MBP) is one of the widely used partners for production of recombinant fusion proteins in E. coli. MBP is among the most effective solubility enhancers. In addition, MBP can be used as an affinity tag for purification of recombinant proteins on a column of amylose resin.

Objectives: The purpose of this study was to investigate the use of rice flour, a natural source of amylose, for purification of MBP fusion proteins.

Materials and Methods: MBP and a fusion protein of MBP and avian influenza virus nucleoprotein (MBP-NP) were expressed in E. coli and subjected to purification by rice flour and a commercial amylose resin. The purified proteins were analyzed by SDS-PAGE.

Results: The results indicated that MBP and MBP-NP, both were successfully purified by rice flour.

Conclusions: Rice flour can be used for purification of MBP fusion proteins. Although the efficiency of purification by rice flour is less than amylose resin, however, the yield is sufficient to obtain a quantity of protein required for research purposes.

Keywords: Maltose-Binding Proteins; Fusion; Protein; Amylose; Purification; Rice; Flour

Copyright @ 2013, Ahvaz Jundishapur University of Medical Sciences; Published by Kowsar Corp.

Article type: Research Article; Received: 18 Mar 2012, Revised: 23 Jun 2012, Accepted: 01 Jul 2012; DOI: 10.5812/jjm.4926

Implication for health policy/practice/research/medical education:

The present study described a simple and inexpensive method for purification of recombinant proteins containing a maltose binding protein tag.

Please cite this paper as:

Neissi A, Seyfi Abad Shapouri M, Ghorbanpoor Najafabadi M, Jaydary A. Using Rice Flour for Purification of Maltose Binding Fusion Proteins Expressed in Escherichia coli. Jundishapur J Microbiol. 6(3);2013; 233-6. DOI: 10.5812/jjm.4926

Copyright (C) 2013, Ahvaz Jundishapur University of Medical Sciences; Published by Kowsar Corp.

This is an Open Access article distributed under the terms of the Creative Commons Attribution License (http://creativecommons.org/licenses/by/3.0), which permits unrestricted use, distribution, and reproduction in any medium, provided the original work is properly cited. 


\section{Background}

Production of proteins by genetically engineered Escherichia coli cells has become well established in biotechnological research. One disadvantage, however, of expressing heterologous proteins in E. coli is that the proteins are frequently expressed as insoluble inclusion bodies (1). One way to avoidthis problem is to fuse the target protein with a highly soluble polypeptide partner.Moreover, the fusion partner, or tag, facilitates the purification process and in several cases the detection of the recombinant protein (2). Maltose binding protein (MBP) is one of the most widely used partner proteins. Maltose binding protein is encoded by the malE gene of E. coli K12.

There is evidence indicating that MBP with an approximate molecular weight of 42.5 kilodaltons, is among the most effective solubility enhancers $(3,4)$. In addition, MBP can be used as an affinity tag for purification of recombinant proteins $(3,4)$. Maltose binding fusion proteins can be purified by a one-step affinity chromatography on cross-linked amylose (5). Commercial amylose resins usually consist ofamylose moiety covalently attached to agarose beads (6).

\section{Objectives}

Due to frequent use of MBP as a fusion partner in our laboratory (7-9) along with the fact that commercial amylose resins are expensive, this study was undertaken to verify the efficiency of a natural source of amylose, rice flour, for purification of $\mathrm{MBP}$ and Avian influenza virus nucleoprotein fused to MBP (MBP-NP).

\section{Materials and Methods}

\subsection{Expression of $M B P$ and MBP-NP Fusion Proteins}

E. coli BL-21 strain was transformed with plasmid pMALc2x (for expression of MBP) or plasmid pMAL-c2x-NP (for expression of MBP-NP) (8) as described previously (10). Subsequent to of the bacteria grown on LB agar medium supplemented with ampicillin, a bacterial colony for each plasmid was selected for expression and purification of the proteins. Therefore, $5 \mathrm{ml}$ of LB broth containing $50 \mu \mathrm{g} / \mathrm{mL}$ ampicillin was inoculated with the bacteria and incubated overnight at $37^{\circ} \mathrm{C}$. The overnight cultures were used to inoculate $500 \mathrm{ml}$ of fresh LB-ampicillin medium containing $2 \mathrm{mg} / \mathrm{mL}$ glucose and incubated at $37^{\circ} \mathrm{C}$ with shaking for about $2.5 \mathrm{~h}$, until the OD600 reached 0.5. Then, Isopropyl$\beta$-D-thiogalactoside (IPTG) (Company Cinnagen, Iran) at a final concentration of $1 \mathrm{mM}$ was added to the bacterial suspensions and incubation continued for an additionaltwo hour at $30^{\circ} \mathrm{C}$. Bacterial cells were harvested by centrifugation at $4000 \mathrm{~g}$ for 10 minutes and suspended in $25 \mathrm{ml}$ column buffer (20 Mm Tris/HCl, pH 7.4,200 Mm NaCl and 1mMM EDTA) and stored at $-20^{\circ} \mathrm{C}$, for future use of protein purification.

\subsection{Purification of the Expressed Proteins}

Bacteria, stored at $-20^{\circ} \mathrm{C}$ were thawed in cold water and again subjected to 2 more rounds of freeze and thawing, followed by sonication performed in short pulses of 15 seconds until the bacterial suspension became clear. The soluble and insoluble fractions of the $E$. coli lysate were separated by centrifugation at $12000 \mathrm{~g}$ for $30 \mathrm{~min}$ at $4^{\circ} \mathrm{C}$. Following centrifugation, the supernatants (soluble fractions) were diluted 1:5 with column buffer and divided in two equal parts for purification on a column of amylose resin (New England Biolabs, USA) or on a column filled by rice flour. For protein purification with amylose resin, $3 \mathrm{ml}$ of packed resin in a column of $1 \times 10 \mathrm{~cm}$ was prepared. To createa column of rice flour, the rice flour was prepared with a domestic mill, extensively washed with tap water and held in water at $4^{\circ} \mathrm{C}$, overnight. Then, a column, similar to the above, with $3 \mathrm{ml}$ of packed rice flour was prepared.

To purify the protein on the column of rice flour, diluted soluble fractions were loaded at a flow rate of $1 \mathrm{ml} / \mathrm{min}$. The flow-through was collected and once more loaded on the column. All preparatory steps of washing the column and protein elution were performed as described for amylose resin (New England Biolabs, USA). Samples of the flow-through of columns after elution with $10 \mathrm{Mm}$ maltose were analyzed by electrophoresis in a 10\% SDS polyacrylamid gel (SDS-PAGE).

\section{Results}

To reveal the results of purification of MBP by amylose resin and rice flour columns, multiple fractions of flowthrough of the columns presumed to contain the purified MBP were collected and analyzed by SDS-PAGE. Figure 1 compares 4 primary fractions of both columns, collected after elution with $10 \mathrm{Mm}$ maltose.

Figure 1. SDS-PAGE Analysis of Flow Through of Amylose Resin and Rice Flour Columns, After Purification of MBP.

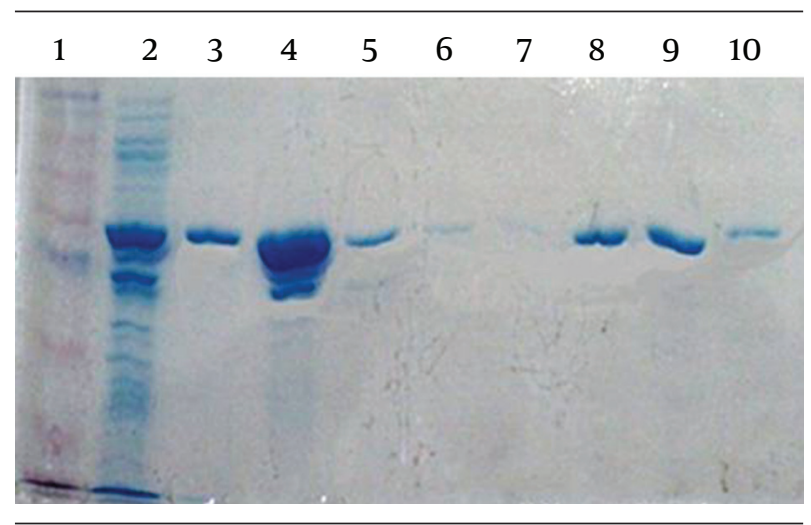

Lane 1: Standard molecular weight (Vivantis, Malaysia), lane 2: bacteria expressing MBP after induction by IPTG, lanes 3-6 and lanes 7-10 represents the first 4 fractions of amylose resin and rice flour columns, respectively 
As projected, application of amylose resin successfully resulted in purification of the pMAL-c2x encoded MBP. It is evident from this figure that rice flour was also able specifically to purify a protein of similar size (about 51 $\mathrm{kDa}$ ) among all of the soluble bacterial proteins loaded on the column. In the subsequent study the ability of rice flour for purification of MBP-NP protein, a proteins of $97 \mathrm{kDa}$, was investigated. The results showed the ability ofrice flour to purify MBP-NP protein (Figure 2).

Figure 2. SDS-PAGE Analysis of Flow Through of Rice Flour Column, After Purification of MBP-NP.

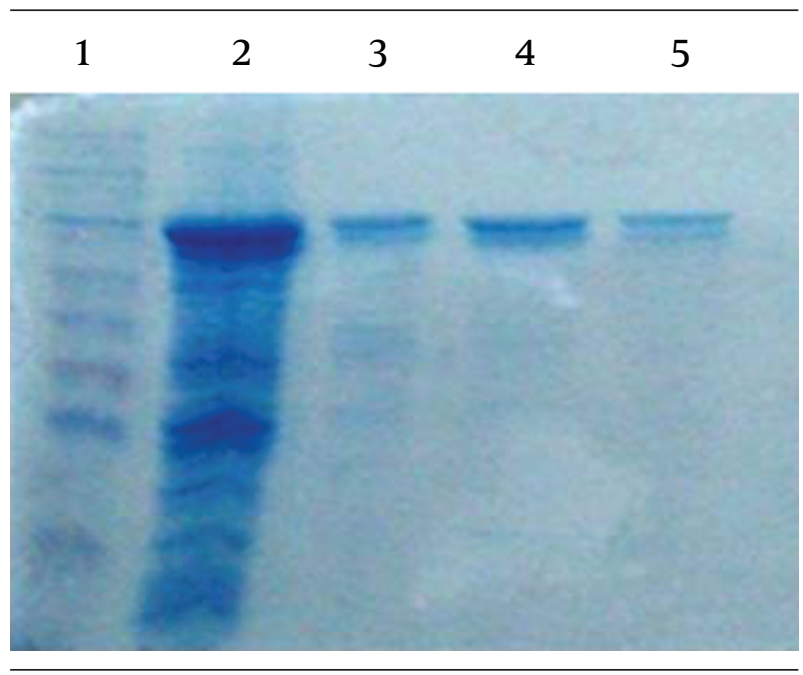

Lane 1: Standard molecular weight (Vivantis, Malaysia), lane 2: bacteria expressing MBP-NP after induction by IPTG, lanes 3-5 represents the first 3 fractions of rice flour column, respectively.

\section{Discussion}

Fusion partners are important tags in protein expression systems. They can be helpful for either stabilizing proteins or enhancing their solubility. Moreover, Tags are important tools for protein purification by affinity chromatography. Tags that are frequently used include hexahistidine (His), glutathione-S-transferase (GST) and maltose binding protein (MBP). Histidine tags have an affinity for nickel or cobalt ions that are coordinate covalent bond with a chelator for the purposes of solid medium entrapment. For elution, an excess amount of a compound able to act as a metal ion ligand, such as imidazole, is used. GST has an affinity for glutathione which is commercially available as glutathione agarose (11).

Up until now, many researchers have preferred to use MBP as a fusion partner, rather than some other affinity tag. The fact is that MBP is a very effective solubilizing agent;it is the only thoroughly validated solubility enhancer that is also a natural affinity tag $(3,4)$. Solubiliz- ing effect of MBP is especially important when eukaryotic proteins are over expressed as fusion proteins in bacteria. The affinity matrix for purifying MBP-fusionproteins utilizes amylose covalently attached to magnetic beads, agarose, or a chemically inert fast protein liquid chromatography (FPLC) matrix (6).

Amylose is one of the two components of starch theother component is amylopectin. Amylose is more resistant to digestion and insoluble in water, compared to amylopectin (12). As a cereal grain, rice is a natural source of amylose (13). In this current study, we tried to findthe utility of rice flour as an alternative to conventional affinity resins for purification of MBP and recombinant proteins fused to MPB. The results indicated that the application of amylose resin and rice flour both lead to purification of a similar protein of $51 \mathrm{kDa}$. MBP is a protein of approximately $42.5 \mathrm{kDa}$ however, when there is no insert in the multiple cloning site of the plasmid pMAL-c2x, fusion of MBP and $\beta$-galactosidase $\alpha$ fragment it leads to expression of a fusion protein that migrates to a position of $51 \mathrm{kDa}$.

In fractions collected of both columns, the amount of purified MBP was increased after the first fractions and then decreased following the second or third fractions. This pattern of increase and decrease of the protein concentration in different fractions confirms the specificity of purifications. Specificity of purifications was also confirmed by the absence of MBP in flow through of columns after washing but before elution (data not shown).

After finding the ability of rice flour in purification of MBP- $\beta$-galactosidase fusion protein, the possibility that purification of the fusion protein is related to $\beta$-galactosidase subunit, should be eliminated. For this purpose, purification of a fusion protein of MBP with nucleoprotein of Influenza virus A (MBP-NP), lacking the $\beta$-galactosidase were investigated. The results illustrated that rice flour was also able to purify MBP-NP with a molecular weight of $97 \mathrm{kDa}$. A very near similar pattern of increase and decrease of the purified protein in different fractions was also observed in this experiment.

Based on the results of this study, it was concluded that rice flour binds specifically the MBP and releases it after elution by maltose solution. Although the quantity of purified protein was significantly lower with rice flour nevertheless, its purity was comparable to the protein purified by amlyose resin. Therefore, rice flour could be used for purification of MBP fusion proteins, at least in laboratories with limited research funds.

\section{Acknowledgements}

None declared.

\section{Authors' Contribution}

None declared. 


\section{Financial Disclosure}

None declared.

\section{Funding/Support}

This study was financially supported by the Shahid Chamran University of Ahvaz, Iran.

\section{References}

1. Lilie H, Schwarz E, Rudolph R. Advances in refolding of proteins produced in E. coli. Curr Opin Biotechnol.1998;9(5):497-501

2. Fox JD, Waugh DS. Maltose-binding protein as a solubility enhancer. Methods Mol Biol. 2003;205:99-117

3. Fox JD, Routzahn KM, Bucher MH, Waugh DS. Maltodextrin-binding proteins from diverse bacteria and archaea are potent solubility enhancers. FEBS Lett. 2003;537(1-3):53-7

4. Terpe K. Overview of tag protein fusions: from molecular and biochemical fundamentals to commercial systems. Appl Microbiol Biotechnol. 2003;60(5):523-33

5. Pattenden LK, Thomas WG. Amylose affinity chromatography of maltose-binding protein: purification by both native and novel matrix-assisted dialysis refolding methods. Methods Mol Biol. 2008;421:169-89

6. Bagheri V, Motamedi H, Seyfiabad Shapouri MR. An Efficient Fusion Protein System for Expression of Bacillus Anthracis Protective Antigen as Immunogenic and Diagnostic Antigen. Asian Pac JTropi Med. 2010:765-768

7. Jaydary A, Seyfiabad SMR, Ghorbanpoor M, Mayahi M. Sequencing and Phylogenetic Analysis of Nucleoprotein Gene from an Avian Influenza Virus Subtype H9N2 Isolated from Ahwaz. Sci Res Iran Vet J. 2011;6(4):20-28

8. Motamedi H, Seyfiabad Shapouri MR, Ghorbanpour Najafabadi $\mathrm{M}$, Arefzadeh N. Cloning and expression of tetanus toxin $\mathrm{C}$ fragment $(\mathrm{Fc})$ in prokaryotic vector for constructing recombinant protein based vaccine for tetanus. Iran JVet Res. 2011;12(2):107-112

9. Chung CT, Niemela SL, Miller RH. One-step preparation of competent Escherichia coli: transformation and storage of bacterial cells in the same solution. Proc Natl Acad Sci U S A.1989;86(7):2172-

10. Berg JM, Tymoczko JL, Stryer L. Biochemistry. 2007.

11. Chung HJ, Liu Q. Impact of molecular structure of amylopectin and amylose on amylose chain association during cooling. Carbohydrate Polymers. 2009;77(4):807-815

12. Hu G, Burton C, Yang C. Efficient measurement of amylose content in cereal grains. J Cereal Sci. 2010;51(1):35-40 